\title{
USO DE FERRAMENTAS DE INOVAÇÃO NA ENGENHARIA AUTOMOTIVA NO PROCESSO DE BLINDAGEM VEICULAR CIVIL COM BASE NO PROGRAMA ROTA 2030 NO BRASIL
}

Guido Muzio Candido (guido.candido@usp.br) - Engenharia Mecânica, Escola Politécnica, USP. Paulo Carlos Kaminski (pckamins@usp.br) - Engenharia Mecânica, Escola Politécnica, USP.

\section{RESUMO}

A engenharia no setor de segurança veicular, em relação à blindagem civil automotiva no Brasil apresenta um crescimento continuo traduzido pelo aumento da violência urbana principalmente nas grandes cidades. Neste contexto, o Brasil é o país que mais possui veículos blindados civis no mundo: são cerca de 16 mil novos emplacamentos de automóveis com proteção balística em 2017, segundo dados do Exército Brasileiro (EB), à frente de países como Estados Unidos, Colômbia e México. Simultaneamente, o recente Programa de incentivo do setor automotivo do Governo aprovado em 2018, denominado de Programa Rota 2030, estabelece, entre os principais objetivos da nova política industrial, o estímulo à geração de inovação por meio da pesquisa e desenvolvimento (P\&D), a continuação da melhoria da sustentabilidade veicular, a evolução da segurança e o aumento da competitividade da indústria automobilística nacional. Motivado pelos fatores expostos, este trabalho tem o objetivo de aplicar as ferramentas de inovação na engenharia automotiva, tais como a inovação aberta e a experiência do usuário, no que se refere ao processo de blindagem veicular civil no Brasil para incrementar os critérios de projeto de segurança balística e apoiando-se nas vantagens tributárias do Programa Rota 2030.

Palavras chave: Indústria automotiva; Blindagem civil veicular; Inovação aberta; Experiência do usuário; Programa Rota 2030. 


\section{INTRODUÇÃO}

Em meados de 2018, o então Presidente da República, Michel Temer, sanciona a Lei 13.755 que regulamenta o Programa Rota 2030. A lei estabelece requisitos para a comercialização de veículos no Brasil, institui o Programa Rota 2030 referente à mobilidade e logística e dispõe sobre o regime tributário de autopeças não produzidas localmente. Dentre os principais objetivos desta política industrial estão o estímulo à geração de inovação por meio da pesquisa e desenvolvimento (P\&D), a continuação da melhoria da sustentabilidade veicular, a evolução da segurança e o aumento da competitividade da indústria automobilística brasileira (ANFAVEA, 2018).

A Lei 13.755/2018 publicada no Diário Oficial da União em dezembro de 2018 estabelece requisitos para os veículos novos comercializados no mercado brasileiro, sejam nacionais ou importados. Os modelos devem participar do Programa Brasileiro de Etiquetagem Veicular (que mensuram o consumo de combustível dos veículos), atender requisitos mínimos de eficiência energética e incorporar novas tecnologias de segurança veicular. São considerados dispêndios estratégicos com P\&D aqueles relativos à manufatura avançada, conectividade, sistemas estratégicos, soluções estratégicas para a mobilidade e logística, novas tecnologias de propulsão ou autonomia veicular e suas autopeças, desenvolvimento de ferramental, moldes e modelos, nanotecnologia, pesquisadores exclusivos, big data [grande conjunto de dados produzidos e armazenados que requerem processamento em tempo tolerável], sistemas analíticos e preditivos (data analytics) e inteligência artificial (ANFAVEA, 2018).

O programa estipula ainda mecanismos para o desenvolvimento da cadeia de autopeças. As empresas que importarem autopeças sem produção equivalente no País, que hoje já possuem alíquota reduzida de imposto de importação a $2 \%$ dentro do regime chamado ex-tarifário, terão esta alíquota reduzida a zero. Em contrapartida, deverão aportar em P\&D o equivalente a estes $2 \%$ através de fundos já existentes ou parcerias com instituições de ciência e tecnologia, universidades, organizações independentes, entre outros (ANFAVEA, 2018).

Em relação à segurança veicular, nas últimas duas décadas, o setor de blindagem automotiva no Brasil apresenta um crescimento continuo traduzido pelo aumento do número de empresas de proteção veicular e de materiais balísticos instalados no Brasil, e consequente aumento do 
controle deste segmento pelo setor militar. Atualmente o Brasil é o maior mercado global de veículos blindados civis com cerca de 16 mil novos emplacamentos de automóveis com proteção balística em 2017, segundo dados do Exército Brasileiro (EB). O México, segundo mercado mundial, produz 7 mil veículos blindados. No ano de 2018 o segmento de blindagem veicular no Brasil emplacou 20 mil unidades com proteção balística, alta de 25\%, em relação à 2017 (adaptado de UOL, 2018).

Neste contexto, todo veículo de passeio blindado no Brasil possui o certificado de registro (CR) emitido pelo EB que vincula o proprietário ao veículo protegido, o qual contém produtos controlados, como por exemplo, vidros blindados e mantas de aramida, onde estes materiais são previamente testados e validados balisticamente no Campo de Provas do Exército (CAEx), no Rio de Janeiro. Os fabricantes destes materiais submetem ao EB amostras singelas destes produtos que são testadas conforme a norma ABNT NBR 15.000-2005. O EB emite um relatório de aprovação de testes, denominado de Relatório Técnico do Exército (RETEx). Os veículos civis blindados, na prática, não são obrigados como um sistema de proteção, a serem testados balisticamente, por não haver a obrigatoriedade tanto pelo EB quanto pela Legislação brasileira. As empresas de blindagem realizam a proteção balística dos veículos adicionando os materiais aprovados com os respectivos números de RETEx, e providenciam a documentação necessária junto ao EB para a certificação e emissão do $\mathrm{CR}$ ao proprietário do automóvel protegido. Por outro lado, também não há procedimentos ou normas específicas no Brasil que regulam ou fiscalizam o desenvolvimento do projeto, do processo e da qualidade técnica de uma blindagem veicular civil. Ou seja, para garantir que não haja vulnerabilidade no processo de proteção do automóvel blindado, o usuário confia seu veículo às expertises automotivas e balísticas dos técnicos responsáveis nas empresas que realizam o serviço de proteção.

Em geral, os automóveis civis são blindados no país depois de vendidos aos clientes nas concessionárias, sem o conhecimento das fabricantes e sem as mesmas garantias originais das montadoras de veículos, denominadas de OEMs, Original Equipment Manufacturers ou Fabricantes Originais de Equipamentos. A qualidade e as garantias relativas à segurança ativa e passiva, corrosão e estrutura da carroceria, sistemas de freios, suspensões, e demais coberturas originais dos veículos, por exemplo, são automaticamente perdidas pelos clientes ao autorizarem o processo de proteção balística nas blindadoras. Os consumidores muitas vezes 
desconhecem as perdas das garantias originais de fábrica de seus automóveis por não haver clareza por parte das concessionárias e das empresas de blindagem de quais são os impactos em garantia nos veículos ao se realizar uma proteção nos mesmos.

De acordo com o portal eletrônico de notícias UOL, Universo online (2018), as estimativas do Exército indicam que há 400 empresas registradas para fazer esse tipo de serviço. Mas quando se restringe à procura de empresas denominadas certificadas pelas fabricantes, esse cenário torna-se limitado: a Land Rover há quatro blindadoras homologadas no Brasil; a BMW trabalha com duas empresas de blindagem certificadas; a Volkswagen é a única das marcas generalistas a certificar uma empresa. Mercedes-Benz, Porsche e Volvo, por exemplo, não trabalham com empresas homologadas. A Audi importa o único modelo blindado de fábrica disponível no mercado nacional, o utilitário Audi Q5 proveniente do México. As montadoras instaladas no Brasil recorrem às blindadoras para produzirem seus veículos blindados com base nos requisitos de mercado, de legislação, governamentais, automotivos e requisitos de proteção balística.

Considerando estas variáveis neste cenário de desenvolvimento no processo de blindagem no Brasil, este trabalho propõe aplicar ferramentas de inovação na engenharia automotiva, tais como a inovação aberta e a experiência do usuário, no que se refere ao processo de blindagem veicular civil no Brasil para incrementar os critérios de projetos de segurança balística automotiva, de legislação, apoiando-se nas vantagens tributárias do Programa Rota 2030.

\section{REVISÃO TEÓRICA}

\subsection{A blindagem veicular civil}

A blindagem veicular civil consiste na proteção balística de um determinado veículo de passageiros, de uso civil, por meio de aplicação de materiais compostos de vidros blindados, aços inoxidáveis e mantas de aramida que são instalados no automóvel por uma empresa especializada, denominada de blindadora, na região do habitáculo de modo a proteger o motorista e os ocupantes contra disparos de armas de fogo. No caso do Brasil para uso em veículos civis, o EB define o uso do padrão de níveis de blindagem norte americana, a NIJ 0108.01 (National Institute of Justice), desde o nível I até o nível III-A para veículos civis, e nível IV para veículos de transporte de valores, os denominados carros-forte. 
Dos componentes agregados ao veículo que promovem a blindagem, o vidro é de longe, o de maior densidade, ou seja, aquele com maior massa agregada por área. Em se tratando de blindagem nível III-A os componentes de proteção aplicados ao veículo possuem as seguintes grandezas (Portal Blindados, 2018):

- Vidros blindados: de 36 a $47 \mathrm{~kg} / \mathrm{m}^{2}$ (conforme tecnologia/composição utilizada);

- Chapas de aço inoxidáveis: cerca de $22 \mathrm{~kg} / \mathrm{m}^{2}$;

- Mantas de fibra de aramida: cerca de $4 \mathrm{~kg} / \mathrm{m}^{2}$.

A localização dos materiais de proteção balística no veículo é ilustrada na Figura 1. Em geral, para as colunas e regiões de menor área, são instalados os aços. Nas regiões de maior área de proteção uniforme, como teto e portas são instaladas as placas de aramida. E por fim, os vidros blindados são instalados nas portas e carroceria.

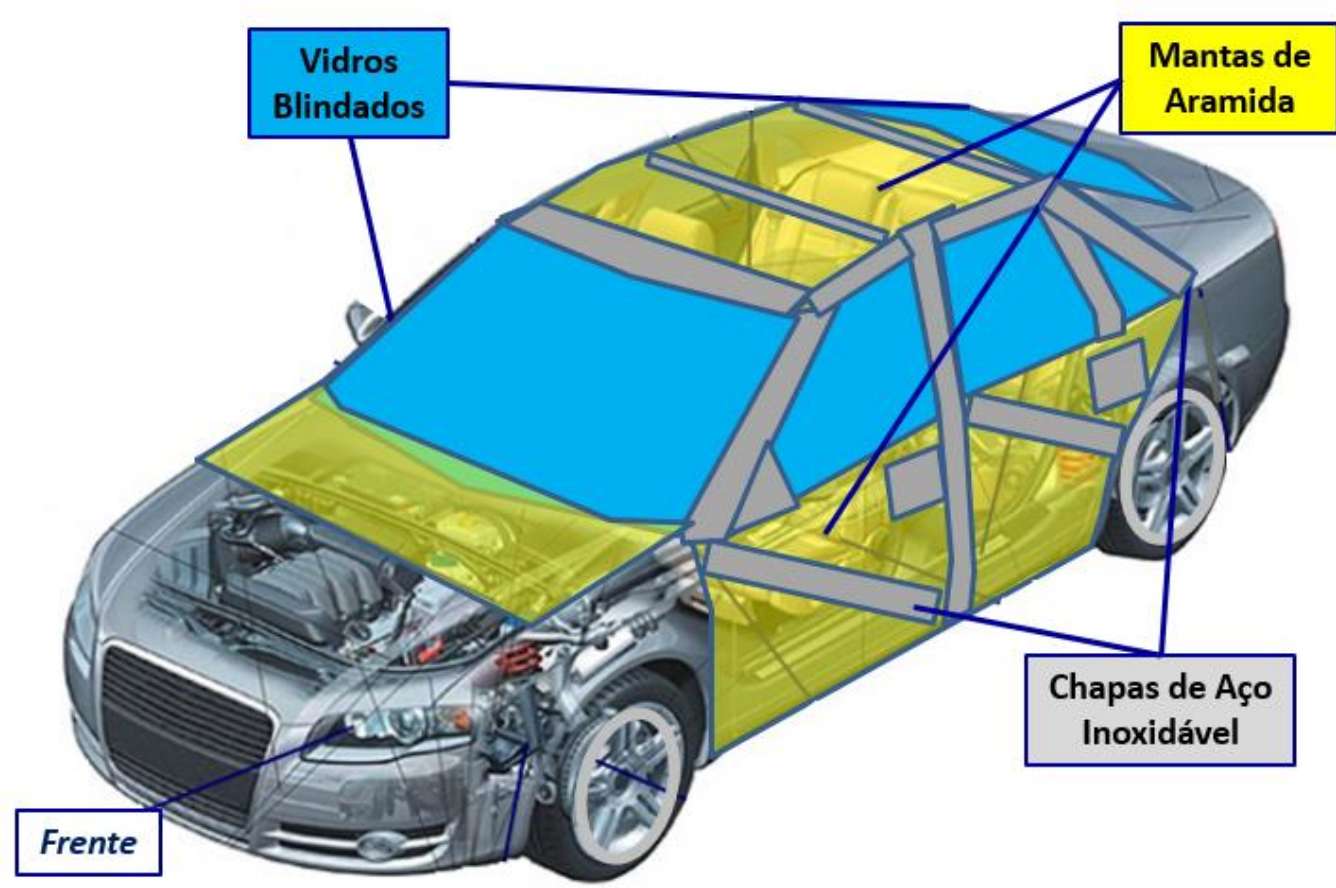

FIGURA 1 - Localização ilustrativa dos materiais de proteção balística em um veículo civil de passageiros.

Fonte: adaptado de Intent Design (2019).

A blindagem instalada no automóvel deve oferecer proteção conforme o nível especificado (NIJ) aos ocupantes no habitáculo do veículo. Os seguintes componentes são adicionados nas atividades de blindagem veicular civil: 
- Vidros blindados nas portas, onde os dianteiros são móveis e os traseiros fixos;

- Estrutura interna metálica das portas, fechaduras, teto e contorno de aço nas portas nas regiões de abertura entre as peças automotivas, denominadas de overlaps;

- Mantas de aramida nas portas, teto e painel traseiro (sedans) e tampa traseiras (SUVs);

- Colunas A, B, C e D (SUVs) dos veículos protegidos com chapas de aço;

- Espelhos retrovisores externos reforçados em sua estrutura;

- Caixa de rodas interna, externa e cinta de aço nas cinco rodas;

- Para-lamas dianteiros e capô de motor;

- Proteção entre o banco traseiro e o porta-malas;

- Instalação de acessórios, pneus com cinta de aço (run flat), sirenes e viva voz externo.

\subsection{Etapas do processo de blindagem veicular}

O fluxo de processos típico de uma blindagem automotiva é apresentado esquematicamente na Figura 2. Após o pedido do cliente e pré-pagamento, a empresa prestadora gera uma ordem de serviço para solicitar os materiais de acordo com o nível de proteção que o proprietário do veículo solicitou. É nesse instante que o processo de blindagem se inicia. O veículo é inspecionado antes de realizar a desmontagem: verifica-se o correto funcionamento do motor, das luzes, dos equipamentos eletrônicos e de segurança; é avaliado se há qualquer dano, e/ou riscos no veículo. Os materiais de proteção, se disponíveis no veículo específico, são selecionados para blindar o automóvel. Se o material de proteção não estiver disponível nas dimensões necessárias, por exemplo, no caso da primeira blindagem de um determinado modelo de veículo na empresa, o processo é continuado medindo a carroceria, portas, colunas, tal como segue-se o projeto de blindagem, o que permite a empresa de cortar e construir os componentes do material balístico necessários para cobrir cada uma dessas áreas. Em seguida, desmonta-se e remove-se os componentes originais do interior do veículo. Para encaixar os vidros blindados das portas, as forrações de acabamento são ajustadas. Outras preparações de veículos são feitas para receber os materiais de proteção, como reorganização dos chicotes elétricos, sem causar danos à funcionalidade original. O processo segue cobrindo a região interna do habitáculo com chapas de aço e mantas de aramida. Em seguida, instala-se as janelas de vidro blindadas. Estas são projetadas para permitir a montagem e posição conforme projeto OEM, dando-lhes um acabamento similar ao original. As peças de acabamento que foram removidas do interior do 
veículo são recolocadas tal como foi recebido. O veículo blindado é concluído e mantém sua aparência original da OEM. Após a realização dos testes estáticos e dinâmicos, o veículo é inspecionado e finalmente entregue ao destino do cliente.

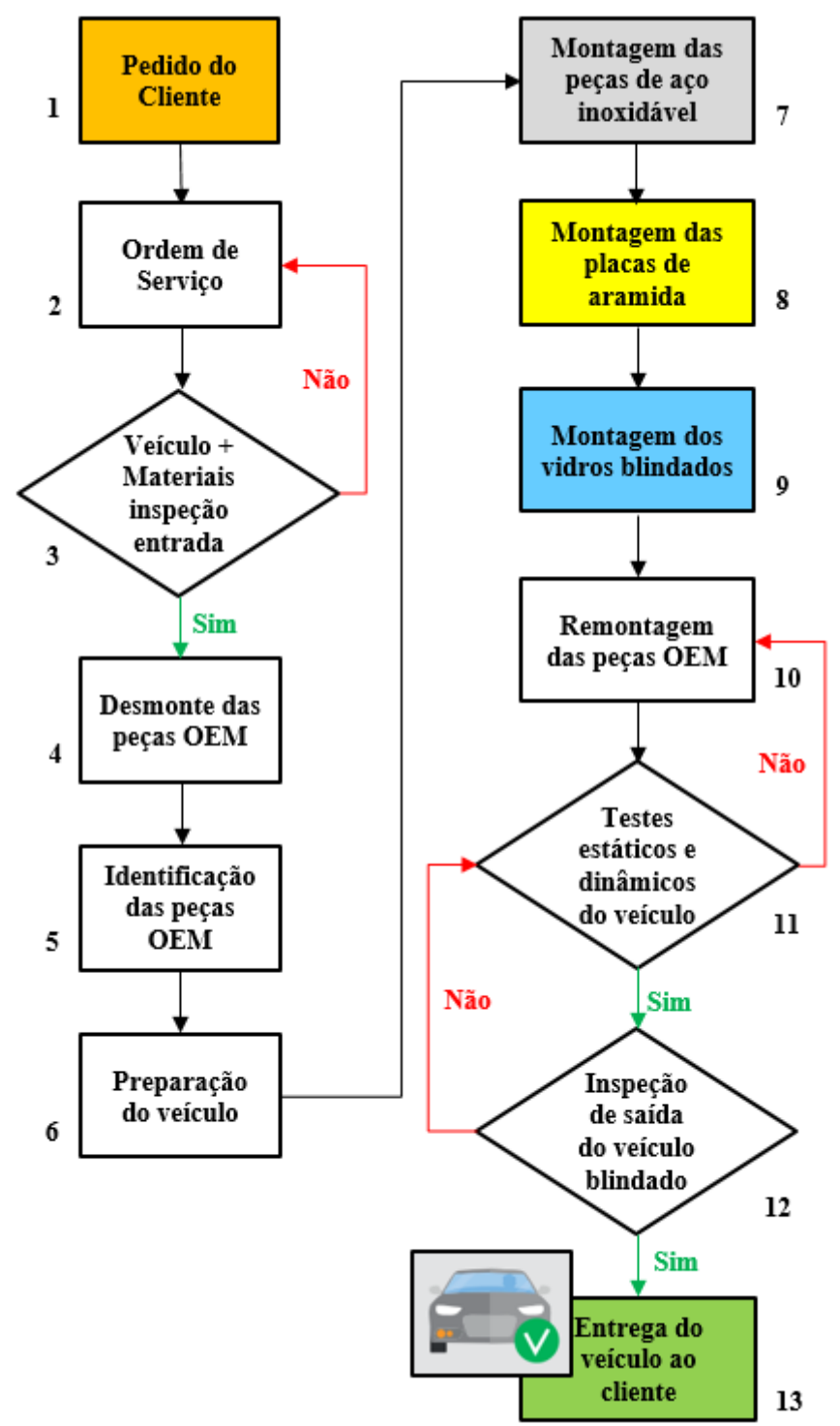

FIGURA 2 - Fluxo de processos de blindagem automotiva. Fonte: autor (2019).

\subsection{Inovação aberta}

A inovação pode ser compreendida como o desenvolvimento ou o aperfeiçoamento de novos produtos e processos. Exemplo disso está na legislação brasileira, que vem inserindo cada vez mais a inovação nas políticas públicas (Armellini et al, 2011). Segundo o $§ 1^{\circ}$ da Lei Federal 11.196, de 2005, considera-se inovação tecnológica como "a concepção de novo produto ou 
processo de fabricação, e a agregação de novas funcionalidades ou características ao produto ou processo que implique melhorias incrementais e efetivos ganho de qualidade ou produtividade, resultando maior competitividade no mercado" (Brasil, 2005).

Na inovação aberta, o processo envolve não só o ambiente interno da organização, mas também o seu entorno, ou seja, clientes, fornecedores, concorrentes e universidades (Chesbrough, 2003a). A inovação aberta possui uma lógica diferente para a geração e aplicação das ideias (Chesbrough, 2003b), com uma abordagem que engloba as novas ideias "de fora para dentro" e "de dentro para fora" (Chesbrough, 2011). Em uma abordagem denominada "de fora para dentro" as empresas utilizam ideias inovadoras a partir de referências externas e as utilizam para criar novos produtos e serviços ou melhorar os produtos e serviços já existentes. Por outro lado, a abordagem "de dentro para fora" permite que as empresas abram as suas ideias de inovação para outras empresas, com intuito de ganho mútuo e compartilhamento de ideias entre si. Chesbrough (2007) afirma ainda que com o aumento dos custos de desenvolvimento e a redução do ciclo de vida dos produtos, as empresas estão encontrando dificuldade em justificar investimentos em inovação. Neste contexto, a inovação aborda ambos os efeitos, otimizando os custos, através do aproveitamento dos recursos de pesquisa e de desenvolvimento externos para economizar tempo e dinheiro no processo de inovação. Modelos de negócios abertos também abordam o lado da receita, através da criação de novas marcas recebendo dinheiro de licenciamento de tecnologias de outras empresas ao redor do mundo.

A fim de analisar "quando" e "como" a inovação aberta ocorre no processo de desenvolvimento de produto, Armellini et. al. 2014 propõem um modelo de inovação em P\&D, apresentado na Figura 3. Neste modelo são identificados os "produtos" internos nas três atividades da estrutura de P\&D de uma organização, ou seja, "conhecimento" como principal produto de pesquisa básica, "tecnologia" para pesquisa aplicada e "produtos" para o desenvolvimento. A combinação de tais ativos são as ideias que permitem a combinação de dados, informações, conhecimentos e tecnologias existentes em novos conhecimentos, tecnologias, produtos ou processos. 


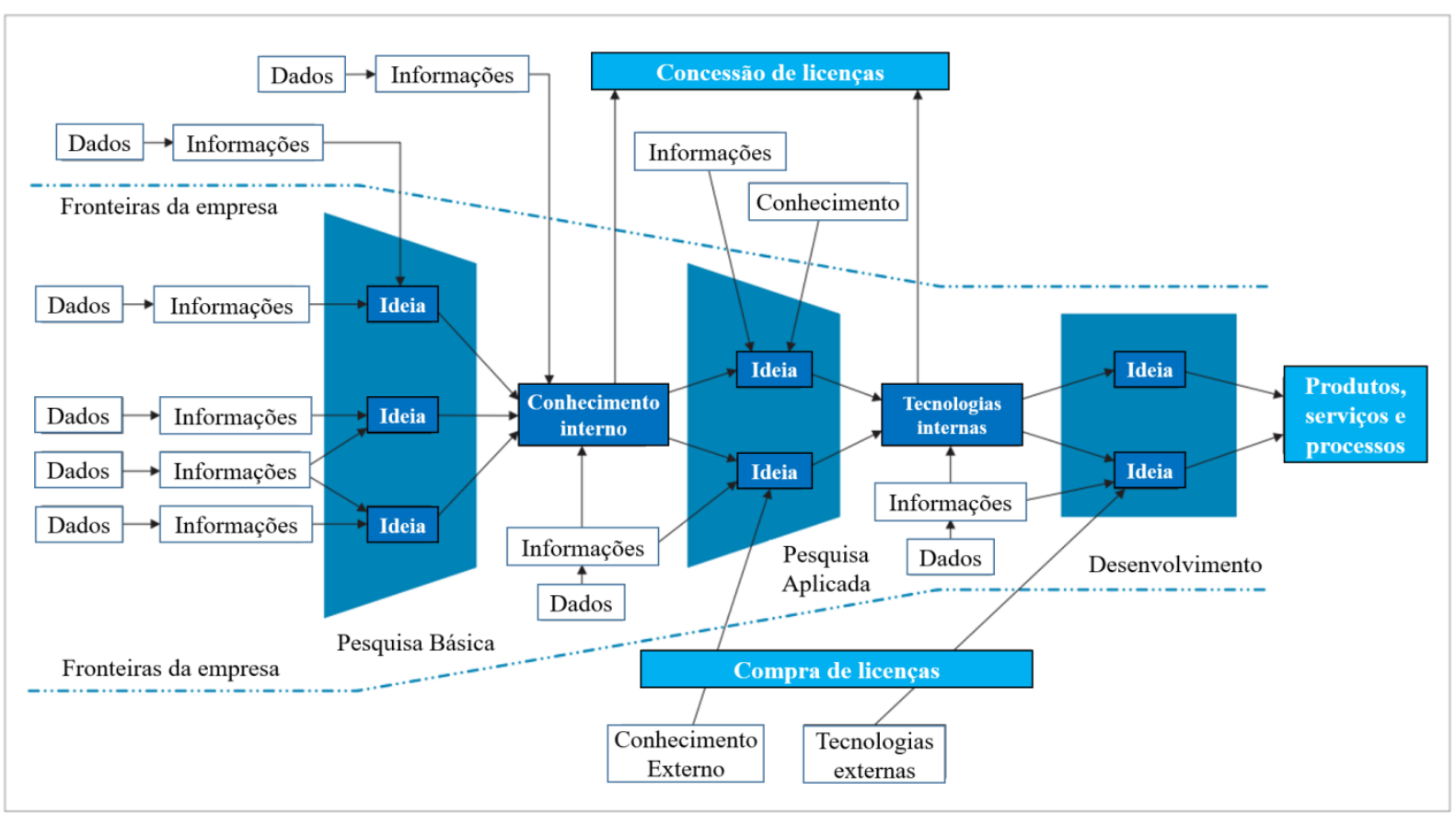

FIGURA 3 - Modelo aberto de desenvolvimento de produto. Fonte: adaptado de Armellini et. al. (2014).

De acordo com Armellini et al. (2012), comparando os segmentos industriais aeroespaciais brasileiros e canadenses, as empresas brasileiras (economia emergente) são mais propensas à inovação aberta, uma vez que muitas vezes dependem muito de conhecimento e expertise externos, porque estas (principalmente fornecedores) não têm estrutura suficiente para realizar toda inovação internamente, ou seja, a inovação aberta não é uma opção, mas uma necessidade para a sobrevivência das firmas na economia da inovação.

Em relação à inovação aberta na indústria automotiva brasileira, geralmente o compartilhamento de ideias ocorre dentro da cadeia de fornecedores com as montadoras quando os envolvidos atuam num mesmo projeto. A participação de usuários no projeto de desenvolvimento de um novo veículo ocorre em sessões da OEM na criação de um novo automóvel, nos quais sem conhecerem a marca ou modelo, os mesmos apontam melhorias e os desejos em relação ao que gostariam de encontrar em um veículo. No caso dos usuários de veículos blindados, estes são raramente participativos no compartilhamento de suas ideias e de suas necessidades às organizações da cadeia, como OEM e fornecedores dos materiais de proteção. 


\subsection{Experiência do usuário}

Existem várias normas, padrões e diretrizes que podem complementar o conhecimento de domínio existente de um projeto de desenvolvimento e ajudar designers e engenheiros automotivos a seguir os fatores humanos básicos e as regras de usabilidade. Simultaneamente, existem normas e diretrizes para o desenho geral de sistemas interativos de projetos automotivos, muitas vezes fornecidos por parceiros das OEMs.

De acordo com a ISO 9241-210:2010 “a experiência do usuário é uma percepção e resposta da pessoa resultante do uso e / ou do uso antecipado de um produto, sistema ou serviço. A experiência do usuário inclui emoções, crenças, preferências, percepções, respostas físicas e psicológicas dos usuários, comportamentos e realizações que ocorrem antes, durante e após o uso. A experiência do usuário é uma consequência da imagem da marca, da sua apresentação, funcionalidade, desempenho do sistema, comportamento interativo e capacidades assistenciais do sistema interativo, estado interno e físico do usuário resultante de experiências anteriores, atitudes, habilidades e personalidade, e o contexto de uso".

\section{METODOLOGIA}

Considerando as diversas variáveis locais no desenvolvimento de projeto de proteção balística automotiva, que envolvem desde as questões de legislação até o comportamento e os requisitos do mercado de veículos blindados no Brasil, tais como a qualidade do serviço e dos materiais de proteção instalados, a metodologia proposta foca na adoção pelas OEMs de práticas de inovação aberta na engenharia automotiva ao desenvolver integralmente no país os automóveis com proteção balística. Através da participação de agentes externos ao projeto de blindagem, ou seja, não somente as blindadoras, propõe-se agregar participações de agentes além das fronteiras das OEMs, tal como exposto na Figura 3. Itens como conhecimento e tecnologias provenientes de agentes externos possuem informações técnicas, de segurança e de legislação que contribuem significativamente com a assertividade no projeto de blindagem.

Desta forma, lista-se a seguir os agentes externos à OEM ao desenvolver um veículo civil a ser blindado com o fornecedor de serviço de blindagem, de modo a obter como resultados, a qualidade do produto e do processo, a satisfação dos clientes finais, e sobretudo, permitir que a 
OEM obtenha os benefícios de isenções de tarifas ou tributos governamentais mediante o atendimento aos requisitos do Rota 2030. Ou seja, além de satisfazer aos usuários, cumpre com as garantias dos serviços e de proteção ao cliente final.

- Universidades: integrar alunos e professores de Engenharia no projeto de blindagem da OEM; auxiliar a equipe de projeto na obtenção de informações referentes à Legislação vigente; auxiliar no entendimento e na aplicação das normas automotivas e balísticas;

- Centros de pesquisa: prover testes em campo e em laboratórios para os veículos e para os materiais de acordo com os requisitos de engenharia da OEM e da demanda balística;

- Fabricantes dos materiais de segurança balística: compartilhar as especificações e recomendações técnicas; apresentar produtos e projetos de inovação com objetivos de redução de massa dos materiais de blindagem sem alteração em desempenho balístico;

- Exército Brasileiro (EB): compartilhar informações sobre a normas militares e critérios de blindagem veicular; apresentar propostas de testes e especificações dos materiais de proteção opaca e transparente; especificar os níveis de blindagem de acordo com a aplicação e com a demanda necessária;

- Usuários: conhecer os problemas de campo que ocorrem com os respectivos veículos protegidos ainda dentro do período de garantia da blindagem; apresentar propostas de ações corretivas e preventivas referente ao produto recebido;

- Governo: prover e orientar as OEMs e blindadoras quanto às informações relativas às isenções de tarifas e tributos do Programa Rota 2030, quando elas promovem a P\&D.

A Tabela 1 apresenta um resumo das principais contribuições dos agentes externos à OEM ao desenvolver um veículo civil a ser blindado, envolvendo blindadora, fornecedores, centros de pesquisas, universidade e clientes finais. 
TABELA 1 - Práticas de inovação colaborativa no desenvolvimento de blindagem veicular civil no Brasil.

\begin{tabular}{|c|c|c|c|}
\hline $\begin{array}{l}\text { Práticas de inovação } \\
\text { colaborativa em blindagem } \\
\text { veicular civil na montadora }\end{array}$ & $\begin{array}{l}\text { Fases do processo de } \\
\text { inovação }\end{array}$ & $\begin{array}{l}\text { Agentes externos à } \\
\text { montadora (OEM) }\end{array}$ & $\begin{array}{l}\text { Contribuição para o produto } \\
\text { veiculo blindado civil }\end{array}$ \\
\hline \multirow[t]{4}{*}{ 1. Colaboração em P\&D } & $\begin{array}{l}\text { - Pesquisa - geração e } \\
\text { seleção de ideias; } \\
\text { - Criação do conceito de } \\
\text { blindagem para o veículo. }\end{array}$ & $\begin{array}{l}\text { - Fornecedores de materiais } \\
\text { de proteção balística; } \\
\text { - Blindadora; } \\
\text { - Cliente (usuário final). }\end{array}$ & $\begin{array}{l}\text { - Capacidade do automóvel } \\
\text { receber atualizações e } \\
\text { novas configurações de } \\
\text { blindagem; }\end{array}$ \\
\hline & - P\&D automotivo & $\begin{array}{l}\text { - Universidades; } \\
\text { - Centros de pesquisas; } \\
\text { - Blindadora. }\end{array}$ & $\begin{array}{l}\text { - Projeto de blindagem do } \\
\text { veículo da OEM; } \\
\text { - Requisitos de engenharia e } \\
\text { da qualidade. }\end{array}$ \\
\hline & - P\&D balístico & $\begin{array}{l}\text { - Fornecedores de materiais } \\
\text { de proteção balística; } \\
\text { - Blindadora. }\end{array}$ & $\begin{array}{l}\text { - Definição da lista de peças } \\
\text { de proteção balística. }\end{array}$ \\
\hline & $\begin{array}{l}\text { - Testes balísticos } \\
\text { (materiais e veicular); } \\
\text { - Testes automotivos } \\
\text { (estático e dinâmico). }\end{array}$ & $\begin{array}{l}\text { - Exército (EB); } \\
\text { - Fornecedores de materiais } \\
\text { de proteção balística; } \\
\text { - Centros de pesquisas; } \\
\text { - Universidades. }\end{array}$ & $\begin{array}{l}\text { - Certificados de materiais } \\
\text { RETEx; } \\
\text { - Resultados de testes de } \\
\text { campo. }\end{array}$ \\
\hline $\begin{array}{l}\text { 2. Colaboração em gestão } \\
\text { de P\&D }\end{array}$ & $\begin{array}{l}\text { - Pesquisa de campo; } \\
\text { - Garantias; } \\
\text { - Pós-vendas. }\end{array}$ & $\begin{array}{l}\text { - Centros de pesquisas; } \\
\text { - Universidades. } \\
\text { - Cliente (usuário final). }\end{array}$ & $\begin{array}{l}\text { - Lições aprendidas; } \\
\text { - Melhoria continuada; } \\
\text { - Requisito de novos } \\
\text { projetos. }\end{array}$ \\
\hline
\end{tabular}

\section{ESTUDO DE CASO}

O estudo de caso da metodologia, foi aplicada em uma montadora premium de veículos europeia instalada no Brasil, juntamente com uma blindadora nacional, uma Universidade pública, três fornecedores de materiais de blindagem, clientes finais (usuários) e o EB, no qual cada agente estava centrado com uma empresa de engenharia de projetos automotivos independente contratada pela OEM, sendo esta última situada na Grande São Paulo. O escopo de entrega do projeto da empresa de engenharia para a OEM foi a realização da blindagem de dois veículos no nível NIJ IIIA em um modelo sedan médio e em um veículo SUV, mantendose para ambos a garantia original de fábrica, comprovados por testes automotivos, dinâmicos e estáticos e por testes balísticos nos materiais de proteção e nos veículos. A contribuição de cada agente externo ao projeto, no caso a contribuição com os estudantes da Universidade, os dados técnicos dos fornecedores de materiais de proteção, o suporte técnico dos engenheiros do EB e os retornos dos usuários, ocorreu de maneira significativa do início ao final do projeto, de modo que as principais ações realizadas pela equipe de projeto são apresentadas na Tabela 2. 
TABELA 2 - Principais contribuições dos agentes externos à OEM com inovação colaborativa e experiência do usuário no desenvolvimento de blindagem veicular civil.

\begin{tabular}{|c|c|c|}
\hline $\begin{array}{l}\text { Agentes externos à montadora } \\
(\mathrm{OEM})\end{array}$ & $\begin{array}{l}\text { Principais contribuições ao projeto do veículo } \\
\text { blindado civil }\end{array}$ & Ações adotadas pela equipe de projeto \\
\hline $\begin{array}{l}\text { 1. Fornecedores de materiais } \\
\text { de proteção balística }\end{array}$ & $\begin{array}{l}\text { Aplicações de materiais específicos ao tipo de } \\
\text { veiculo e à posição de instalação. }\end{array}$ & $\begin{array}{l}\text { Desenhos das peças com dimensões e especificações } \\
\text { técnicas dos materiais de blindagem adequadas a cada } \\
\text { função e posição de montagem nos veículos. }\end{array}$ \\
\hline 2. Blindadora & $\begin{array}{l}\text { Atendimento aos requisitos de engenharia do } \\
\text { veículo da OEM, provenientes dos cadernos de } \\
\text { encargos. }\end{array}$ & $\begin{array}{l}\text { Atendimento às garantias dos requisitos de: } \\
\text { - Segurança do automóvel (bolsas inflaveis, cintos de } \\
\text { segurança, bancos do motorista e passageiro); } \\
\text { - Qualidade (esforços de abertura e fechamento das } \\
\text { portas, suspensão das rodas, altura do solo do veículo); } \\
\text { - Eficiência: consumo de combústivel, admissível. }\end{array}$ \\
\hline 3. Cliente (usuário final) & $\begin{array}{l}\text { Reclamações de campo e não conformidades: } \\
\text { - Ruídos e vibrações durante o movimento; } \\
\text { - Erros do sistema eletrônico central; } \\
\text { - Esforços excessivos e desgastes prematuros; } \\
\text { - Qualidade ótica dos vidros blindados. }\end{array}$ & $\begin{array}{l}\text { Inclusão dos clientes na participação do projeto de } \\
\text { melhorias para solucionar as falhas de campo. }\end{array}$ \\
\hline 4. Exército Brasileiro (EB) & $\begin{array}{l}\text { Especificação das normas de blindagem e dos } \\
\text { tipos de munições e suas energias de impacto. }\end{array}$ & $\begin{array}{l}\text { Preparação dos materiais de blindagem conforme as } \\
\text { normas ABNT. }\end{array}$ \\
\hline 5. Universidades & $\begin{array}{l}\text { Recursos humanos e no suporte ao projeto } \\
\text { (estudantes de engenharia, programa de estágio). }\end{array}$ & $\begin{array}{l}\text { Inclusão dos estudantes no processo e projeto de } \\
\text { blindagem. }\end{array}$ \\
\hline 6. Centros de pesquisas & $\begin{array}{l}\text { Suporte à realização dos testes dinâmicos, } \\
\text { estáticos e balísticos dos materiais e dos veículos. }\end{array}$ & $\begin{array}{l}\text { Realização dos testes conforme definido no escopo do } \\
\text { projeto. }\end{array}$ \\
\hline
\end{tabular}

\section{CONCLUSÃO}

Este trabalho teve como finalidade apresentar uma proposta de adicionar as ferramentas de inovação aberta e de experiência do usuário no desenvolvimento de projeto de veículos blindados civis no Brasil, através de uma proposta de intercâmbio e colaboração de agentes externos à tradicional equipe de projetos de modo a promover a interação destes agentes com engenheiros e fornecedores definidos pela OEM. Com a inclusão de Universidades, Centros de Pesquisas, o EB e os próprios usuários dos automóveis blindados, pretende-se ampliar mais os dados de defeitos de campo, de pesquisas entre usuários, além do envolvimento dos próprios fabricantes dos produtos de proteção, como os vidros blindados e as placas de aramida. Com estes dados dos agentes externos estabelece-se uma significativa relação da OEM com os critérios de avaliação de engenharia para a melhoria continuada e aplicação de lições aprendidas dos projetos automotivos de blindagem. Com efeito, esse método permite melhorar a qualidade do produto e limitar a ocorrência de defeitos em campo por meio de ações preventivas de maior confiabilidade. 
As atividades de inovação tecnológica são etapas científicas, tecnológicas, organizacionais, financeiras e comerciais, incluindo investimentos em novos conhecimentos que, na verdade, pretendem ou levam à implementação de produtos e processos tecnologicamente novos ou aprimorados. É justamente nas ações inovativas de P\&D na indústria automotiva, que o Programa Rota 2030 atua, com o objetivo de estimular na cadeia de produção veicular novas formas e novos projetos de inovação com redução de impostos.

\section{REFERÊNCIAS}

ANFAVEA - ASSOCIAÇÃO NACIONAL DOS FABRICANTES DE VEÍCULOS AUTOMOTORES. Programa Rota 2030 é sancionado e publicado no Diário Oficial da União. 2018. Disponível em: http://www.anfavea.com.br/docs/11.12.18_Press_Resultados_Rota\%202030.pdf. Acessado em 08/04/2019.

ARMELLINI F.; AQUINO, L.N. D; SILVEIRA, F. F. Inovação tecnológica e propriedade intelectual: desafios da engenharia de produção na consolidação do Brasil no cenário econômico mundial. XXX ENEGEP Encontro Nacional de Engenharia de Produção. 2011.

ARMELLINI F.; KAMINSKI, P. C.; BEAUDRY, C. Integrating open innovation to new product development - the case of the Brazilian aerospace. International Journal of Technological Learning Innovation and Development, Vol. 5, No. 4, 2012.

ARMELLINI F.; KAMINSKI, P. C.; BEAUDRY, C. The open innovation journey in emerging economies: an analysis of the Brazilian aerospace industry. Journal of Aerospace Technologic Management. São José dos Campos, Vol. 6, No. 4, 2014.

ASSOCIAÇÃO BRASILEIRA DE NORMAS TÉCNICAS. NBR ISO 15000: Sistemas de blindagem, Rio de Janeiro, 2005.

BRASIL. Lei 11.196, de 21 de novembro de 2005, Capítulo III. Institui incentivos à inovação tecnológica. 2005.

CHESBROUGH, H.W. The era of open innovation. MIT Sloan Management, 44(3), pp. 35-41. 2003a.

CHESBROUGH, H.W. The logic of open innovation: managing intellectual property. California Management Review, 45(3), pp. 33-58. Disponível em: http://dx.doi.org/10.2307/41166175. 2003b.

CHESBROUGH, H.W. Why companies should have open business models. MIT Sloan Management Review, v. 48, n.2, p. 22-28, 2007.

CHESBROUGH, H.W. Bringing open innovation to services. MIT Sloan Management Review, 52(2), 85-90. 2011.

INTENT DESIGN. Automotive and transportation. Disponível em: https://www.intent-design.com/automotiveand-transportation. Acessado em 26/04/2019.

INTERNATIONAL STANDARD. ISO 9241-210 Ergonomics of human-system interaction - Part 210: human-centred design for interactive systems. First edition 2010-03-15.

UOL - UNIVERSO ON LINE. 2018. Dá para comprar carro blindado de fábrica no Brasil? Opções são escassas. Disponível em: https://carros.uol.com.br/noticias/redacao/2018/04/18/da-para-comprar-carro-blindadode-fabrica-no-brasil-opcoes-sao-escassas.htm. Acessado em 20/05/2019.

U. S. DEPARTMENT OF DEFENSE. National Institute of Justice. NIJ Standard 0108.01. Ballistic Resistant Protective Materials. 1985. Disponível em https://www.ncjrs.gov/pdffiles1/nij/099859.pdf. Acessado em 05.06.2019. 